\title{
A RECORDING APPARATUS FOR MEASURING THERMAL CONDUCTIVITY, AND SOME RESULTS OBTAINED WITH IT IN SOIL ${ }^{1]}$
}

Documentatio R. H. A. VAN DUIN and D. A. DE VRIES

Laboratory of Physics and Meteorology, Agricultural University, Wageningen (Director : Prof. W. R. van Wijk)

\section{ABSTRACT}

An automatic apparatus is described for measuring the thermal conductivity of soil by a non-stationary method. By means of the apparatus 36 measuring elements are successively switched on, and the thermal conductivity near such an element is recorded.

From the thermal conductivity the moisture content of the soil is ascertained, and, from repeated measurements, the evapotranspiration as well. The measurements are carried out to a depth of $90 \mathrm{~cm}$ in sandy field soil covered with grass and in a weighable evapotranspirometer $25 \mathrm{~cm}$ in depth. The results of the indirect determinations of the moisture content agree fairly well with the direct determinations by weighing. The degree of accuracy of the calculated evapotranspiration is sufficient if periods of the order of 1 week are considered (see Fig. 7).

\section{INTRODUCTION}

Since water is an important factor in plant growth, agriculture is highly interested in the moisture content of the soil in the root zone, and in the variations which occur in it, both with time and depth. One of the authors (DE VRIES, 1952) has developed an indirect method of measuring the moisture content, based on the thermal conductivity of the soil. This method has the advantage, as compared with other methods, that the time lag and disturbance of the soil are negligible; the moisture content determined in this way, however, is only representative of a small volume of soil.

For several purposes - e.g., in order to determine the evapotranspiration of a field soil - it is desirable to know the changes in moisture content to a rather great depth, and at short intervals. To satisfy these requirements a great number of measurements are desired, which would be very timeconsuming if the observations had to be carried out by hand. A recording apparatus has therefore been designed, which, in conjunction with an automatic switching system, performs the observations.

To test the moisture contents obtained in this way, some of the measurements were carried out in a "Poporf evapotranspirometer", with the object of comparing the results thus obtained with direct determinations. These Popof F pots are weighable cylinders $25 \mathrm{~cm}$ in depth and $25 \mathrm{~cm}$ in diameter, with a bottom of fine gauze.

\section{The METHOD OF MEASUREMENT}

A non-stationary method of determining the thermal conductivity of soil has been described in a previous paper (DE VRIEs, 1952 a). It is based on the logarithmic rise of temperature with time of an infinite line source, situated in a homogeneous medium. In practice this source is approximated by an

1) Received for publication March 5, 1954. 
electrically heated wire, while the temperature rise $(\Theta)$ is measured near the middle of the wire by means of a thermojunction.

In formula ${ }^{2}$ )

(1) $\Theta=\frac{q}{4 \pi \lambda}(\ln t+c)$

for the heating, and

(2) $\Theta=\frac{q}{4 \pi \lambda} \ln \frac{t}{t-t^{\prime}}$

for the cooling of the junction,

$q=$ amount of heat produced per unit of time and unit of length of the source;

$\lambda=$ thermal conductivity of the material;

$t=$ time expired since commencement of heating;

$t^{\prime}=$ duration of heating;

$c=$ a constant.

The heating wire and the thermocouple leads are situated in a needleshaped probe about $13 \mathrm{~cm}$ in length, and $0.13 \mathrm{~cm}$ in diameter, which is introduced into the soil horizontally.

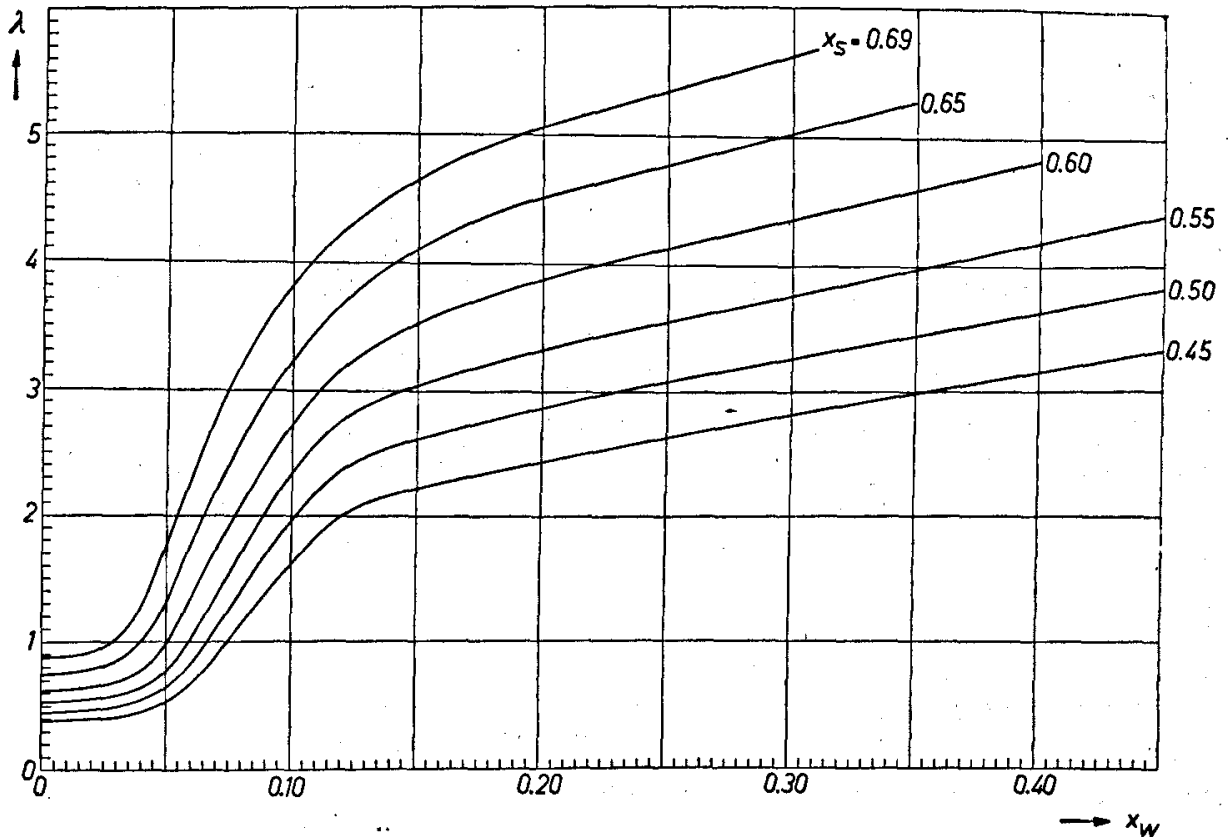

Fig. 1. Relation Between the thermal conductivity $\lambda$ (in millicals $/ \mathrm{cm} / \mathrm{sec} /{ }^{\circ} \mathrm{C}$ ), and THE VOLUME FRACTION OF WATER $x_{w}$, FOR DIFFERENT VOLUME FRACTIONS OF SOLID MATERLAL $x_{s}$.

The rise of temperature is measured with a sensitive galvanometer. The second junction is placed in the soil, at the same depth as the warm junction. The change in deflection of the galvanometer due to temperature changes in the soil is therefore small, and can be corrected for by measuring it for several minutes before heating.

The moisture content of the soil can be deduced from its thermal conduc-

2) These formulas do not apply for values of $t$ and $t-t^{\prime}$ below about 10 seconds. 
tivity, after their relation (Fig. 1) has been established. This may be done either experimentally, or by a theoretical computation starting from the volume fractions and the thermal conductivities of the constituents (DE. VRIEs, $1952 \mathrm{~b}$ ). In practice both methods are combined.

If the precipitation and the changes in moisture content are known down to a sufficient depth, it will be possible to calculate the evapotranspiration, assuming that the moisture content of the soil shows no large variations in the horizontal sense. To this end 36 elements were introduced into the soil, i.e., three groups, each comprising nine elements, were placed in the field soil at depths of $3,6,10,16,24,35,50,70$ and $90 \mathrm{~cm}$, and the remaining elements were placed in the Poporf pots.

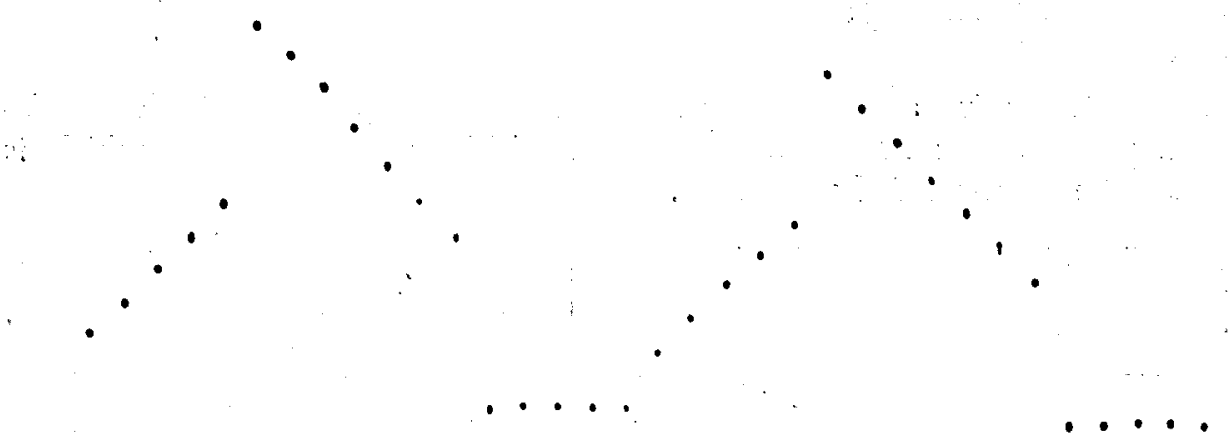

Fig. 2. EXample of a Photographic Record $; 1 \mathrm{~cm}$ in this figure corresponds to $3 \mathrm{~mm}$ on the film. The gradient of the lines is a measure of the thermal conductivity.

Every ten minutes the apparatus switches on an element. The deflection of the galvanometer is recorded photographically. The apparatus is constructed in such a way that straight lines are obtained on the film (Fig. 2), instead of logarithmic curves, for both the heating and cooling periods. The thermal conductivity can be found direct from the gradients of these lines.

\section{Switching}

Switching over from one element to the next is effected by means of rotating cylinders with contact strips. The heating and thermocouple circuits are separated, i.e., each circuit has its own contact cylinders. Each heating wire is connected to an adjustable resistance ( $R$ in Fig. 4), in order to obtain a suitable heating current adapted to the relevant thermal conductivity. The contact time of a thermocouple is ten minutes, that of a heating wire about three minutes. The length of the cocrresponding contact strips is adapted to these times. The precise duration of heating, which is the same for all elements, viz. $165 \mathrm{sec}$ ' 'is'governed by a central regulating system, described below.

\section{ReCording the MEASUREMENTS}

The film is exposed at suitable time intervals, which are selected so that the light spot moves the same distance between successive exposures (see Figs. 2 and 3). These intervals, counted from the commencement of heating, considered as zero, form a geometric series for the heating part of the curve 

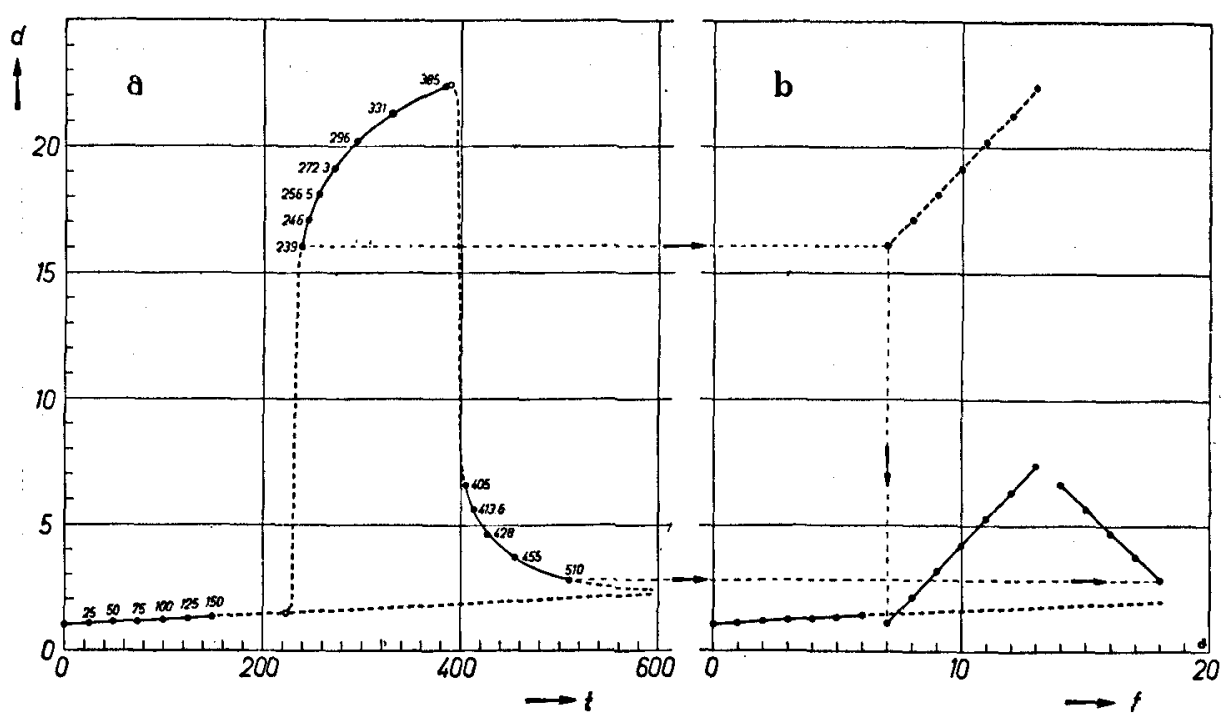

Fig. 3a. The deflection of the galvanometer $d$ (in mm), as a function of time $t$ (in sec.). The circles in broken lines refer to commencement $(t=225)$ and termination ( $t=390)$ of heating. The film is exposed at the times indicated by the circles in unbroken lines.

3b. Straight Lines ARE OBTAINEd BY MOVING THE FILM THROUGhout a CONSTANT DISTANCE AFTER EACH EXPOSURE.

The great deflection of the galvanometer during the first seconds of heating is compensated by a constant voltage, which is switched on and off by a relay governed by the heating current.

(see Fig. 3), and can be computed from Eq. (2) for the cooling part. After each occasion on which the lightspot is photographed, the film is moved throughout the same distance, and in this way a straight line is obtained. Both the shutter and the film protractor are operated by means of an electromagnet, regulated by a turning disc with contact strips at distances corresponding to the calculated time intervals. The first reliable point is usually obtained about ten seconds after the commencement or termination of heating.

\section{The regulating system (Fig. 4)}

When the heating current is switched on (contact 2), it starts a synchronous motor (M) by means of the relay 3 . This motor drives several discs, with a rotation time of nine minutes. These discs govern the timing of shutter and film protractor, and regulate the contacts 4 and 5 . Contact 4 fixes the duration of heating, viz. 165 seconds, while 5 stops the motor at the end of the nineminute period. As contact 5 opens 10 seconds after the motor starts, the motor continues to run after the heating current is interrupted, because the relay 6 is closed when 5 is open, and vice versa.

Since the period for one element is ten minutes, and that of the regulating system nine minutes, this system is again at rest in its original position when the cycle of the next element starts. The situation during the rest period is represented in the figure by the fully drawn contacts; contact 4 is closed 


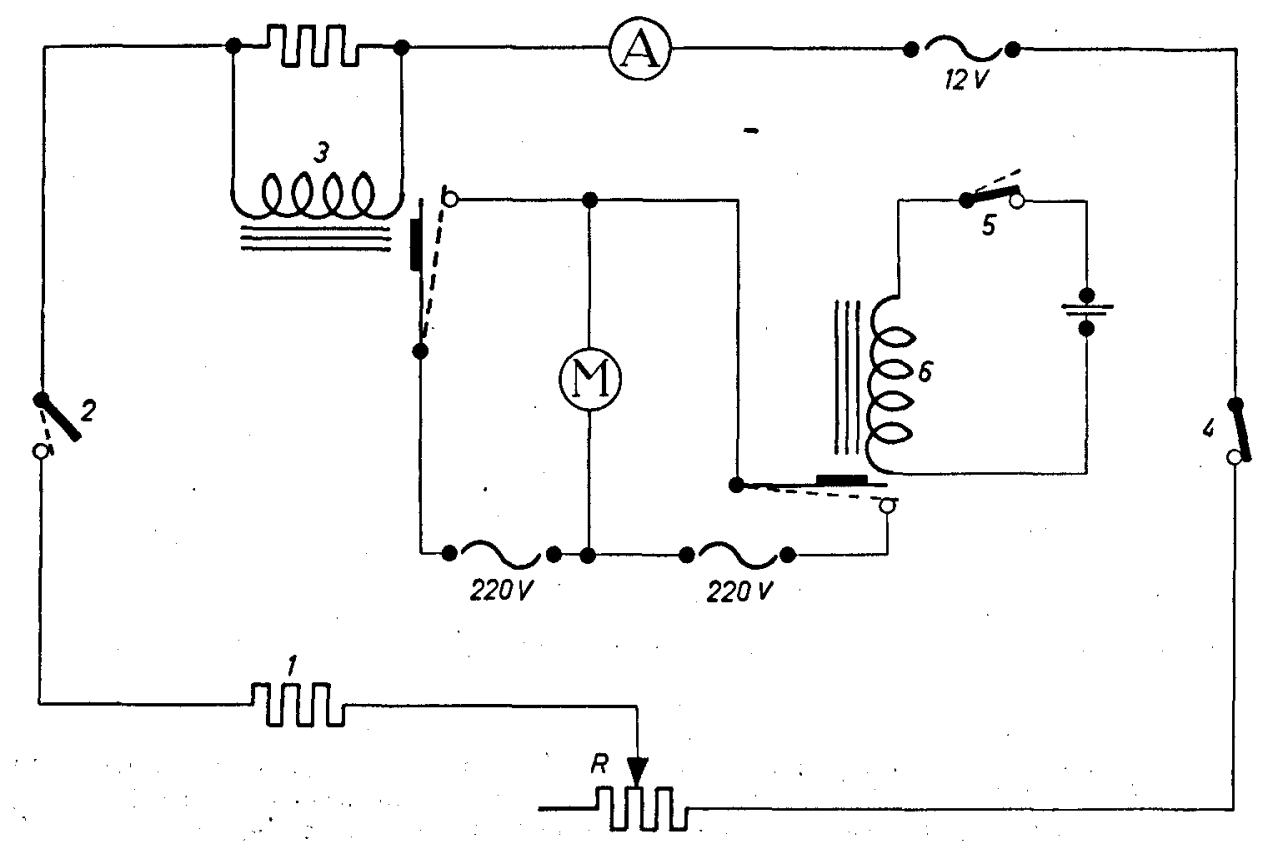

Fig. 4. Cmcuit diagram of the regulating system: heating wire (1) with adjustable resistance (R) and corresponding drag contact (2), with a contact time of three minutes. Relay (3), that starts the motor (M), is governed by the heating current. The latter is started by (2) and interrupted by (4), $165 \mathrm{sec}$ afterwards. Contact (5) regulates the relay (6) in such a way that the motor continues to run when the heating current is switched off, until the recording period of one element has elapsed.

before the motor stops. The contacts drawn in dotted lines refer to the situation between 10 and $165 \mathrm{sec}$ after commencement of heating ${ }^{3}$ ).

\section{Results}

The measurements described here were carried out in sandy soil covered with grass. Figures 5, 6 and 8 refer to the measurements with one of the three groups in field soil. The decrease in thermal conductivity during the dry period of Aug. 4-20 is confined to the upper $35-50 \mathrm{~cm}$ (Fig. 5).

The changes in moisture content during this period are represented in Fig. 6 , in which the moisture content of the deeper layers is considered to be constant. The evapotranspiration in two-day periods is oompared with the potential evapotranspiration (Fig. 8), calculated bij Penman's formula, together with the measured and weighed evapotranspiration in one of the PopofF evapotranspirometers.

The distribution of moisture according to depth in the cylinder with five measuring elements is shown in Fig. 7. The moisture content at wilting point is about 6 vol. $\%$, as the grass was near wilting at the end of the dry period.

3) Some technical details of secondary importance are not described here. They mainly concern the way in which the elements are connected to the switching system, the circuit diagram of the different elements, avoidance of sparks in interrupting the contacts which operate the electromagnets, and the optical system used in obtaining a fine lightspot. Full details of the apparatus will be readily supplied on request. 


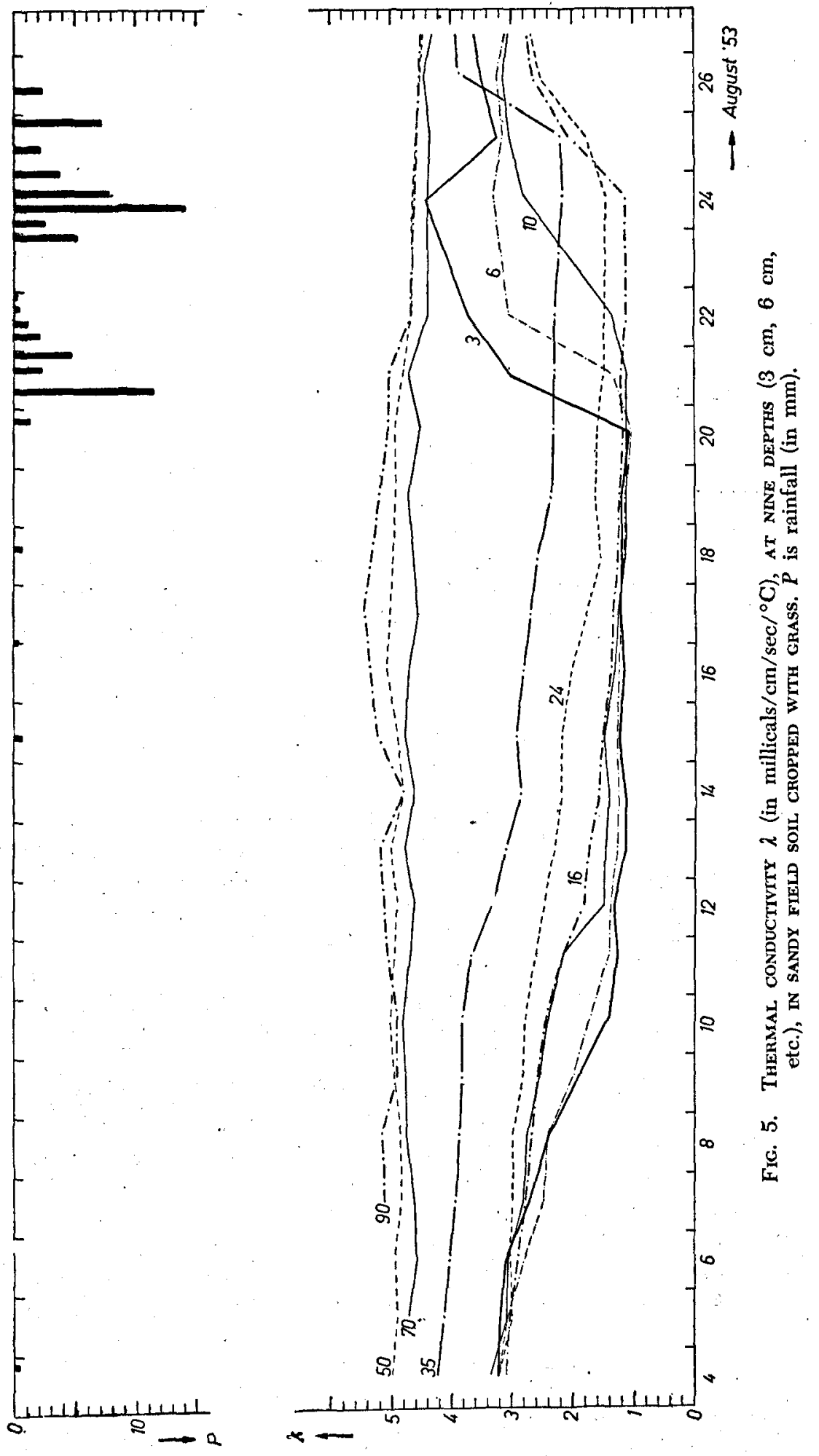




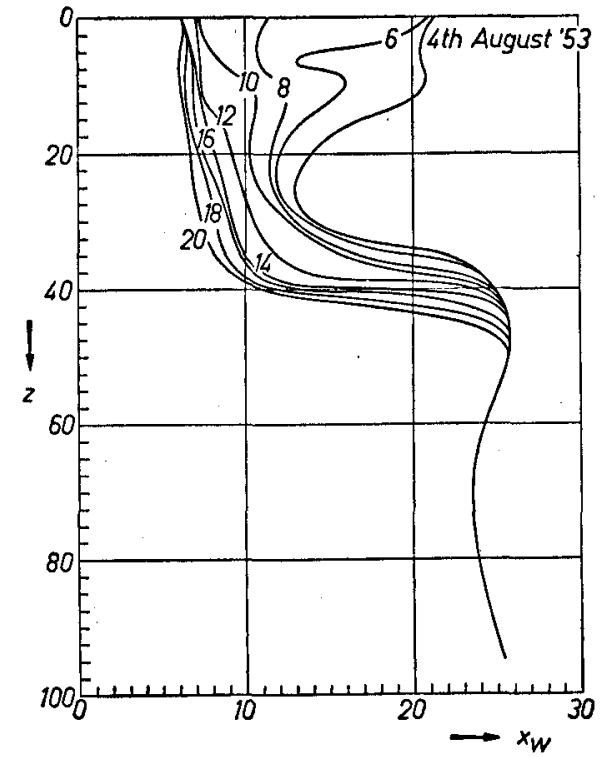

Fig. 6. Relation Between the volume FRACTION OF WATER $x w$, AND THE DEPTH $z$ (in $\mathrm{cm}$ ), in a field soil.



Fic. 7. Relation Between the volume FRACTION OF WATER $x_{w}$, AND THE DEPTH $z$ (in $\mathrm{cm}$ ), in a POPOFF evapotranspirometer. The fully drawn lines refer to a period of drying, the dotted lines to a period of wetting.

\section{Discussion}

In order to determine moisture content from thermal conductivity it is necessary to know the volume fraction of solid material near the measuring element (Fig. 1). The accuracy of a direct determination is limited because the soil in horizontal direction is not homogeneous, least of all in the upper layers. In the Popoff evapotranspirometers these volume fractions were determined from thermal conductivity measurements when the soil was saturated.

Since, in sandy soils, the steep section of the calibration curves coincides with the moisture range between field capacity and wilting point, such a soil was chosen for this investigation.

The distance of the element from the surface must be at least $2 \mathrm{~cm}$, since at smaller distances the temperature of the heating wire during the measuring period is influenced by the thermal properties of the air adjacent to the surface. In this investigation the first element was at a depth of $3 \mathrm{~cm}$, so there was some uncertainty concerning changes in moisture content in the first two $\mathrm{cm}$ below the surface, especially in rainy periods.

The root mean square of the percentile differences between weighed and measured evapotranspiration was $13 \%$ for the two-day periods, while the largest and smallest deviations between weighed and measured values were 58 and $3 \%$ respectively. The difference for the whole period of the measurements reported here was $1 \%$. It follows that, with the present standard of accuracy of the measuring apparatus, the calculated evapotranspiration will only be exact if longer periods are considered.

The method is especially suited for observing the changes in moisture 


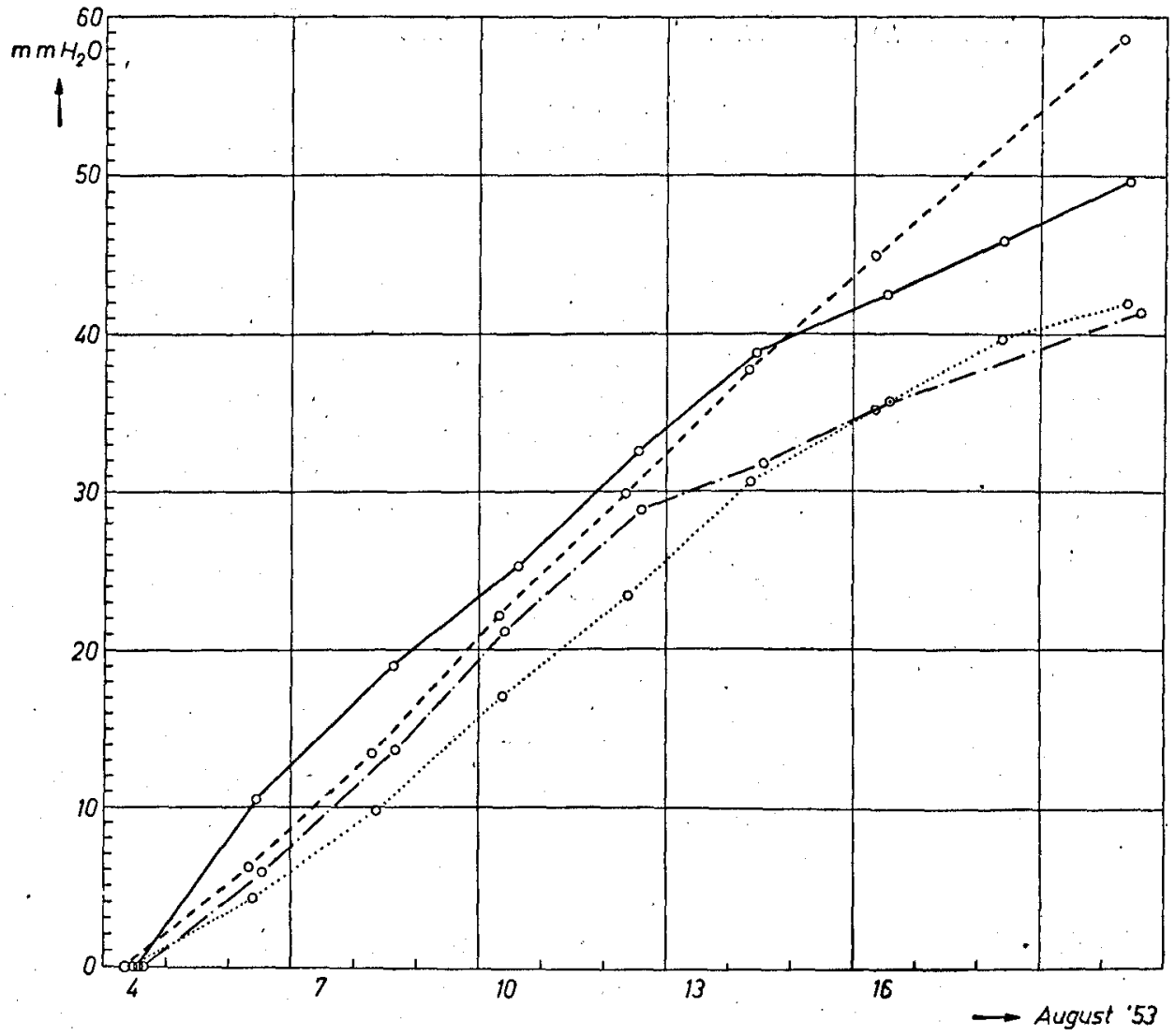

Fig. 8. CoMparison of EVAPOTRANSPIRATTON FigURES OBTAINED IN DIFFERENT WAYS.

. . . . . . . potential evapotranspiration calculated with PenMan's formula (1948). evapotranspiration of a field soil, determined from thermal conductivity measurements.

evapotranspiration in a POPOFF evapotranspirometer, determined from daily weighing.

-. - . . - evapotranspiration in this Popoff pot determined from thermal conductivity measurements.

content in lysimeters, because of the ease with which the volume fraction of the soil near the measuring elements may be determined.

On account of the complicated and vulnerable nature of the apparatus, the method lends itself only for experiments near a laboratory or any other place where adequate technical resources are at hand.

\section{BiBLIOGRAPHY}

Penman, H. L. : Natural evapotranspiration from open water, bare soil and grass. Proc.

Roy. Soc. A 193 (1948), 120-146.

VRIES, D. A. DE : A non-stationary method for determining thermal conductivity of soil in situ. Soil science 73 (1952), 83-89.

VRIEs, D. A. DE: Het warmtegeleidingsvermogen van grond. Med. Landbouwhogeschool 52 (1952), Verh. 1, 1-73. 